This is the accepted version of the article:

Albalad J., Carné-Sánchez A., Grancha T., Hernández-López L., Maspoch D.. Protection strategies for directionally-controlled synthesis of previously inaccessible metal-organic polyhedra (MOPs): The cases of carboxylate: The amino-functionalised Rh(ii)-MOPs. Chemical Communications, (2019). 55. : 12785 - . 10.1039/c9cc07083d.

Available at: https://dx.doi.org/10.1039/c9cc07083d 


\title{
Protection strategies for directionally-controlled synthesis of previously inaccessible metal-organic polyhedra (MOPs): the cases of carboxylate- and amino-functionalised Rh(II)-MOPs
}

\author{
Jorge Albalad, ${ }^{a}$ Arnau Carné-Sánchez, ${ }^{* a}$ Thais Grancha, ${ }^{a}$ Laura Hernández-López ${ }^{a}$ and Daniel Maspoch*ab \\ ${ }^{a}$ Catalan Institute of Nanoscience and Nanotechnology (ICN2), CSIC and The Barcelona Institute of Science and Technology, \\ Campus UAB, Bellaterra, 08193 Barcelona, Spain. E-mail: arnau.carne@icn2.cat; daniel.maspoch@icn2.cat \\ ${ }^{\mathrm{b}}$ ICREA, Pg. Lluís Companys 23, 08010 Barcelona, Spain
}

\begin{abstract}
Herein we report that strategic use of protecting groups in coordination reactions enables directional inhibition that leads to synthesis of highly functionalised metal-organic polyhedra (MOPs), rather than of the extended coordination networks. Using this approach, we functionalised two new porous cuboctahedral Rh(II)-based MOPs with 24 peripheral carboxylic acid groups or 24 peripheral amino groups.
\end{abstract}

Undesired side reactions are the most common limitation in chemical synthesis. ${ }^{1-4}$ Even when the simplest protocol is followed, any minor misstep can lead to wasteful side-products, leading to the costly path of having to start over. A persistent challenge in avoiding side reactions is to ensure that the chemistry in question occurs exclusively at the targeted functional group(s). ${ }^{5-7}$ This has led to development of a broad arsenal of protecting groups and methods for their use, including separate steps for protection and subsequent deprotection of the group(s) whose reactivity is to be temporarily blocked. ${ }^{8}$ In Organic Chemistry, protecting groups confer polyfunctional molecules with chemoselective and orthogonal reactivity, opening up unprecedented reaction pathways for synthesis of active principles, including polymers and peptides with pre-defined sequences of monomers ${ }^{9,10}$ and amino acids. ${ }^{6,711-15}$ In Coordination Chemistry, protecting groups have proven essential for introducing sensitive moieties inside the pore walls of metalorganic frameworks (MOFs) $)^{16,17}$ and/or for controlling the framework interpenetration of MOFs. ${ }^{18}$

Herein, we report that protecting groups can also be used to synthesise previously inaccessible coordination assemblies: specifically, we have developed chemistry to prepare functionalised porous metal-organic polyhedra (MOPs) rather than the extended coordination networks that normally form in the absence of protection strategies. Fig. 1 illustrates our strategy for synthesising a cuboctahedral $\mathrm{Rh}$ (II)-based MOP with 24 available carboxylic acid moities located at its periphery (hereafter called $\mathrm{COOH}-\mathrm{RhMOP}$ ). The synthesis of this class of MOPs entails assembly of 1,3-benzenedicarboxylic acid $\left(\mathrm{H}_{2}\right.$ bdc) derivatives and $\mathrm{Rh}(\mathrm{II})-\mathrm{Rh}(\mathrm{II})$ paddlewheels, in which the 5-position of the bdc derivative dictates the outer functionality of the MOP. ${ }^{19}$ Accordingly, the synthesis of COOH-RhMOP requires use of 1,3,5-benzenetricarboxylic acid ( $\mathrm{H}_{3}$ btc) as the linker. However, as expected, reaction of $\mathrm{Rh}(\mathrm{II})$ with $\mathrm{H}_{3}$ btc tends to form extended coordination networks instead of the desired COOH-RhMOP. This is because the three carboxylic groups react with $\mathrm{Rh}(\mathrm{II})$, extending the material uncontrolledly. Consequently, conventional MOP-synthesis conditions (DMA, $\mathrm{Na}_{2} \mathrm{CO}_{3}, \sim 100^{\circ} \mathrm{C}$; detailed synthesis in $\mathrm{ESI}_{-}^{\dagger}$ ), afford an extended coordination polymer in the form

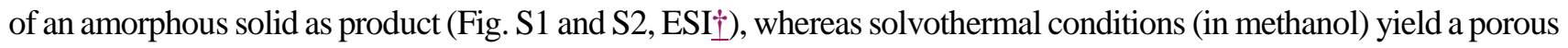
coordination polymer. ${ }^{20}$

Our protection strategy comprises three steps. Firstly, one of the three carboxylic groups of the linker 1,3,5benzenetricarboxylic acid $\left(\mathrm{H}_{3} \mathrm{btc}\right)$ is protected, which provides stoichiometric control over the coordination of two of the three chemically equivalent $\mathrm{COOH}$ functionalities in H3btc. Secondly, the protected linker is reacted with Rh acetate, such that the aforementioned stereochemical control hinders the extension of the coordination network, thereby favouring the formation of the zero-dimensional MOP. Finally, chemoselective deprotection of the protected $\mathrm{COOH}$ affords $\mathrm{COOH}-\mathrm{RhMOP}$, in which 24 carboxylic acid moieties are accommodated at its periphery. 
We began our study by carefully selecting an appropriate protecting group. We sought one that would be sufficiently robust to endure the conditions for the $\mathrm{Rh}$ (II)-MOPs synthesis (i.e., strong basic media and temperatures of up to $100{ }^{\circ} \mathrm{C}$ ) and be amenable to quantitative and chemoselective deprotection. To this end, we revisited the work of Barrett et al., who had previously described a controlled semi-deprotection of a 2-(trimethylsilyl)ethyl-protected (TSE) dicarboxylic acid by stoichiometric addition of fluoride. ${ }^{21}$ Since TSE is kinetically stable under basic conditions, we reasoned that it would be suitable for MOP protection.

We first synthesised the mono-protected $\mathrm{H}_{2}$ btc-COOTSE acid derivative, using a three-step route (Fig. 2; detailed synthesis in $\mathrm{ESI} \dagger$ ). Initially, $\mathrm{H}_{3}$ btc was converted to its triacyl chloride counterpart in situ, through reaction with $\mathrm{SOCl}_{2}$. Then, the triacyl chloride product was reacted with 3 mol. eq. of 2-(trimethylsilyl)ethanol and pyridine to obtain the tri-protected intermediate tris(2-(trimethylsilyl)ethyl)benzene-1,3,5-tricarboxylate (btc-COOTSE 3 ). Finally, stoichiometric deprotection of btc-COOTSE 3 , using 2 mol. eq. of a tetrabutylammonium fluoride solution (1.0 $\mathrm{M}$ in tetrahydrofuran) in two successive additions, followed by a final protonation step, afforded the mono-protected $\mathrm{H}_{2} b t c-$ COOTSE. The purity of the obtained tri-protected intermediate and the mono-protected $\mathrm{H}_{2}$ btc-COOTSE were monitored by ${ }^{1} \mathrm{H}$ NMR and ESI-MS (Fig. S3-S5, ESI†), and no further purification steps were required for the synthesis of COOH-RhMOP.

We then performed the complexation reaction by mixing the mono-protected $\mathrm{H}_{2}$ btc-COOTSE linker with $\mathrm{Rh}$ acetate in $N^{\prime} N$-dimethylacetamide (DMA) under solvothermal conditions $\left(100{ }^{\circ} \mathrm{C}, 48\right.$ hours). Water was used to precipitate out COOTSE-RhMOP from the supernatant, which was a green solid. The product was sequentially washed and finally, dried under vacuum. MALDI-TOF analysis revealed a peak at $\mathrm{m} / z=9890.3$, matching the theoretical value for a cuboctahedral $\mathrm{Rh}$ (II)-based MOP of formula $\left(\left[\mathrm{Rh}_{24}(\mathrm{COOTSE}-\mathrm{bdc})_{24}\right]+\mathrm{H}^{+}\right)^{+}($expected $m / z=$ 9891.5; Fig. 2b, Fig. S6, ESI $\dagger$ ). Additionally, ${ }^{1} \mathrm{H}$ NMR (acetone- $d 6$ ) further confirmed the formation of a zerodimensional architecture featuring 24 TSE protecting groups at its periphery $(\delta=8.85,8.45,4.35,1.28,0.05 \mathrm{ppm})$ (Fig. S7, ESI†).

Next, we did a subsequent deprotection step by reacting COOTSE-RhMOP with 24 mol of a tetrabutylammonium fluoride solution (1.0 M in tetrahydrofurane) for 6 hours. The precipitated product was isolated, washed with diethyl ether, $1.0 \mathrm{M} \mathrm{HCl}$ and water, and finally, dried under vacuum. ${ }^{1} \mathrm{H}$ NMR (DMSO-d6) confirmed quantitative fading of the TSE signals (at $\delta=0.05 \mathrm{ppm}, 1.28 \mathrm{ppm}$ and $4.35 \mathrm{ppm}$ ) with appearance of a new signal at $\delta=13.4 \mathrm{ppm}$, which we attributed to the free $\mathrm{COOH}$ groups (Fig. S9, ESI+口). MALDI-TOF analysis showed a peak at $\mathrm{m} / z=7439.4$ (Fig. $3 \mathrm{~b}$ and Fig. S10, ESI $\dagger)$, which matched accordingly with the estimated formula $\left(\left[\mathrm{Rh}_{24}(\mathrm{COOH}-\mathrm{bdc})_{24}\right]+\right.$ $\left.\mathrm{H}^{+}\right)^{+}$(expected $m / z=7441.5$ ). As expected, the deprotection step rendered these MOPs significantly more porous than the corresponding parent MOPs. Thus, whereas COOTSE-RhMOP was non-porous to $\mathrm{N}_{2}, \mathrm{COOH}-\mathrm{RhMOP}$ showed a BET surface area $\left(S_{\text {BET }}\right)$ of $198 \mathrm{~m}^{2} \mathrm{~g}^{-1}$ (Fig. S11 and S12, ESI $\mathrm{CO}_{2} \mathrm{~g}^{-1}$ for COOTSE-RhMOP to $2.0 \mathrm{mmol} \mathrm{CO} \mathrm{g}^{-1}$ for COOH-RhMOP (Fig. 2c). The increase of gas uptake observed after the deprotection step is attributed to the removal of the TSE bulky groups from the surface of the $\mathrm{Rh}$ (II)MOP akin to similar examples in which a decrease in surface functionalisation of molecular cages caused a beneficial effect on their porous properties. ${ }^{22}$

Carboxylic acids typically have moderately low $\mathrm{pKa}$ values (i.e., $\mathrm{p} K_{\mathrm{a}}=3$ to 5). Therefore, at near-physiological $\mathrm{pH}$, they tend to be deprotonated. Accordingly, $\mathrm{COOH}-\mathrm{RhMOP}$ dissolved in water upon addition of 1 mol. eq. (i.e., 24 mol per MOP) of $\mathrm{NaOH}(\mathrm{pH}=10.5$ ), rendering a negatively-charged MOP, as evidenced by the z-potential value derived by Dynamic Light Analysis measurements (Fig. S14, ESI†). MALDI-TOF analysis of the solution revealed a peak at $m / z=7945.6$ (Fig. S15, ESI $\left.\mathrm{H}^{+}\right)^{-}$(expected $\mathrm{m} / z=7947.0$ ). After confirming the solubility of COOH-RhMOP in basic $\mathrm{pH}$, we ran a pH calibration curve to identify the lowest $\mathrm{pH}$ at which the cage would be water soluble. After the addition of $6 \mathrm{~mol}$ of $\mathrm{NaOH}(25 \%$ of $\mathrm{COOH}$ groups deprotonated), the MOP fully dissolved in water, giving a final $\mathrm{pH}$ value of $\mathrm{pH}=8.2 .{ }^{1} \mathrm{H} \mathrm{NMR}$ of 
the product after it had been in aqueous solution for 7 days did not reveal any signs of scaffold degradation (Fig. S16, ESI†).

Inspired by our previous results, we then aimed to extend our MOP-protection chemistry by endeavouring to incorporate functionalities that had previously been inaccessible in Rh-based materials. The strong affinity of Rh(II) paddlewheels towards $\mathrm{N}$-donor groups precludes the synthesis of a $\mathrm{NH}_{2}$-tagged $\mathrm{Rh}$ (II)-based MOP, unlike with other metal sources. Amino groups are among the most exploited functional groups in the literature, owing to their basicity, dominant nucleophilicity and versatility, as they can be transformed into myriad products under diverse conditions. This has led to the generation of a rich catalogue of amine chemistry. Moreover, amino-functionalized materials can exhibit enhanced physicochemical properties and have been thoroughly used in many applications, such as surface anchoring, carbon dioxide capture, water uptake and pollutant removal. ${ }^{23,24}$

We explored the possibility of protecting the reactive $\mathrm{NH}_{2}$ moiety of 5-aminoisophthalic acid with a suitable protecting group to synthesise the desired MOP. Note that, as in the formation of COOH-RhMOP, direct reaction of Rh acetate with 5-aminoisopthalic acid under the same reaction conditions produced an extended coordination network in the form of an amorphous solid (Fig. S1 and S2, ESI†). As protecting group, we chose tert-butyloxycarbonyl (Boc), given its excellent stability in basic media and its compatibility with free carboxylates. Thus, we synthesised a Bocprotected version of the linker $\left(\mathrm{H}_{2}\right.$ bdc-NBoc) by reacting 5-aminoisophthalic acid with di-tert-butyldicarbonate $\left(\mathrm{Boc}_{2} \mathrm{O}\right)$ in a mixture $(1: 1 \mathrm{v} / \mathrm{v})$ of dioxane and $1 \mathrm{M} \mathrm{NaOH}$ (Fig. 3 and Fig. S18, ESI $\dagger$ ). ${ }^{25}$ This linker was then reacted with $\mathrm{Rh}$ acetate and $\mathrm{Na}_{2} \mathrm{CO}_{3}$ in DMA at $100{ }^{\circ} \mathrm{C}$ for 48 hours. The solids were discarded, and the supernatant was precipitated with diethyl ether and washed with a $1 \mathrm{M} \mathrm{NaOH}$ solution and water. The formation of NBoc-RhMOP was confirmed by MALDI-TOF $\left(\mathrm{m} / z=9110.1\right.$; expected 9105.4) and ${ }^{1} \mathrm{H}$ NMR $(\delta=9.24,8.40$ and $1.41 \mathrm{ppm})$ (Fig. $3 b$ and Fig. S19 S20, ESI+口).

Finally, we deprotected the NBoc-RhMOP by following a standard procedure of stirring it in a solution of trifluoroacetic acid (TFA; 9 mol. eq. vs. MOP) in the dichloromethane for a few hours. ${ }^{1} \mathrm{H}$ NMR and UV-vis analysis of the obtained supernatant (Fig. S22 and S23, ESI†) did not reveal any signals of leached 5-aminoisophthalic acid linker or partial degradation, thereby confirming the robustness of the MOP under the deprotection conditions. The crude product was then neutralised with a triethylamine solution in acetone, washed with methanol and acetone, and characterised by ${ }^{1} \mathrm{H}$ NMR and MALDI-TOF (Fig. $3 \mathrm{~b}$ and Fig. S24, S25, ESI†). Both techniques confirmed that the deprotection had been quantitative. Likewise, ${ }^{1} \mathrm{H}$ NMR analysis evidenced generation of free amino moieties in the $\operatorname{MOP}(\delta=5.32 \mathrm{ppm})$ and quantitative fading of all the previous NBoc signals $(\delta=9.50 \mathrm{ppm}$ and $1.42 \mathrm{ppm})$. In addition, MALDI-TOF analysis in DMSO revealed a peak at $\mathrm{m} / \mathrm{z}=6899.2$ consistent with the formula of the fully deprotected $\mathrm{Rh}-\mathrm{MOP}\left[\mathrm{Rh}_{24}\left(\mathrm{NH}_{2}-\mathrm{bdc}\right)_{24}+\mathrm{H}^{+}+\mathrm{DMSO}^{+}\right.$(expected $\mathrm{m} / z=6895.3$ ).

Next, we explored an alternative route for the deprotection of NBoc-RhMOP in the solid state, reflecting on the fact that the Boc group can undergo thermolabile deprotection without any reagents, solvents or neutralisation step. ${ }^{17,26}$ To this end, we ran a thermogravimetric analysis (TGA) on NBoc-RhMOP to identify the weight-loss attributable to the thermolabile deprotection (Fig. S26, ESI $\doteq$ ). The thermogram clearly showed a step of $24.9 \%$ weightloss in the region between $150{ }^{\circ} \mathrm{C}$ to $200{ }^{\circ} \mathrm{C}$, owing to the thermolytic cleavage of $24 \mathrm{Boc}$ groups in $\mathrm{CO}_{2}$ and isobutylene ( $25.1 \%$ based on theoretical mass). Afterwards, we ran an isothermal experiment at $150{ }^{\circ} \mathrm{C}$ for 6 hours to confirm that no further degradation of the MOP would occur. After the initial weight loss attributable to solvent loss and the deprotection itself, the curve plateaued until the end of the measurement, thus confirming the robustness of the scaffold (Fig. S27, ESI士́). MALDI-TOF analysis of the crude product further confirmed the thermolytic cleavage, with a peak at $m / z=7066.3$ matching with the formula $\left[\mathrm{Rh}_{24}\left(\mathrm{NH}_{2}-\mathrm{bdc}\right)_{24}+\mathrm{H}^{+}+\mathrm{H}_{2} \mathrm{O}+3 \mathrm{DMSO}\right]^{+}($expected $m / z=7066.3)$ (Fig. 3b and Fig. S25, ESI†口).

Analogously to the deprotection of COOTSE-RhMOP, the deprotection of NBoc-RhMOP (either by thermolysis or by treatment with TFA) yielded a product that was more porous than the corresponding starting material. Thus, whereas the $\mathrm{S}_{\text {BET }}$ of the NBoc-RhMOP was $59 \mathrm{~m}^{2} \mathrm{~g}^{-1}$, upon deprotection, the resultant $\mathrm{NH}_{2}-\mathrm{RhMOP}$

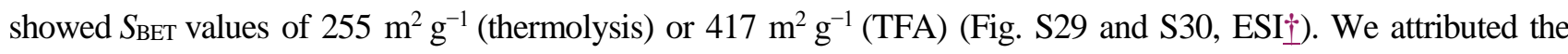
difference in $S_{\mathrm{BET}}$ between these two products to their different morphologies: the thermolytic deprotection of NBoc- 
RhMOP yields micrometric particles (Fig. S31, ESI $\dagger$ ), whereas the TFA-based method yields an amorphous powder composed of aggregated nanoparticles $(c a .50 \mathrm{~nm})$. These values echo the previously reported trend that MOPs exhibit greater gas sorption upon miniaturisation. ${ }^{27}$ Furthermore, the $\mathrm{CO}_{2}$ uptake measured at $298 \mathrm{~K}$ also increased after deprotection, as depicted in Fig. 3c. Thus, whereas the NBoc-RhMOP adsorbed $0.88 \mathrm{mmol} \mathrm{CO}_{2} \mathrm{~g}^{-1}$, the deprotected products $\left(\mathrm{NH}_{2}\right.$-RhMOPs) exhibited uptakes of $1.39 \mathrm{mmol} \mathrm{CO}_{2} \mathrm{~g}^{-1}$ (thermolysis) and $1.52 \mathrm{mmol} \mathrm{CO}_{2} \mathrm{~g}^{-1}$ (TFA) at 1 bar under the same conditions (Fig. 2c). Remarkably, both the $S_{\mathrm{BET}}$ and $\mathrm{CO}_{2}$ uptake values for these $\mathrm{NH}_{2}-\mathrm{RhMOP}^{-}$ products are significantly higher than for their $\mathrm{Cu}$ (II) analogue (non-porous to $\mathrm{N}_{2} ; \mathrm{CO}_{2}$ uptake $=0.70 \mathrm{mmol} \mathrm{CO}_{2} \mathrm{~g}^{-1}$ ). ${ }^{28}$

In conclusion, we have demonstrated strategic use of protecting groups for directionally-controlled coordination chemistry synthesis of $\mathrm{Rh}$ (II)-based MOPs with previously inaccessible functionalities. Using our orthogonal protection/deprotection process, we prepared two new $\mathrm{Rh}$ (II)-based MOPs with 24 peripheral $\mathrm{COOH}$ or $\mathrm{NH}_{2} \mathrm{moieties}$, without affecting the structural integrity or microporosity. Owing to their strong processability, the protected $\mathrm{Rh}$ (II)based MOPs can be then deprotected either in solid state or in solution. Moreover, we dissolved COOH-RhMOP in water at near-neutral $\mathrm{pH}$. Interestingly, the presence of 24 directional $\mathrm{COOH}$ or $\mathrm{NH}_{2}$ groups in a zero-dimensional porous scaffold might be of particular interest for Reticular Chemistry.

This work was supported by the Spanish MINECO (Projects RTI2018-095622-B-I00), the Catalan AGAUR (Project 2017 SGR 238), the ERC, under the EU-FP7 (ERC-Co 615954), and the CERCA Program/Generalitat de Catalunya. ICN2 is supported by the Severo Ochoa programme from the Spanish MINECO (Grant No. SEV-20170706). A. C. S. and T. G. thank the Spanish MINECO for Juan de la Cierva fellowships (IJCI-2016-29802 and FJCI2017-31598). J. A. acknowledges the Generalitat de Catalunya for an FI fellowship (2016FI B 00449).

\section{Conflicts of interest}

The authors declare that there are no conflicts of interest in this publication.

\section{Notes and references}

1 D. Lei, D.-C. Lee, A. Magasinski, E. Zhao, D. Steingart and G. Yushin, ACS Appl. Mater. Interfaces, 2016, 8, 2088-2096.

2 Y. Liu, L. Wang, L. Cao, C. Shang, Z. Wang, H. Wang, L. He, J. Yang, H. Cheng, J. Li and Z. Lu, Mater. Chem. Front., 2017, 1, 2495-2510.

3 S. Li, H. Cai, J. He, H. Chen, S. Lam, T. Cai, Z. Zhu, S. J. Bark and C. Cai, Bioconjugate Chem., 2016, 27, $2315-2322$.

4 J. Kuwabara, Y. Fujie, K. Maruyama, T. Yasuda and T. Kanbara, Macromolecules, 2016, 49, 9388-9395.

5 G. B. Bloomberg, D. Askin, A. R. Gargaro and M. J. A. Tanner, Tetrahedron Lett., 1993, 34, 4709-4712.

6 A.-B. M. Abdel-Aal, G. Papageorgiou, R. Raz, M. Quibell, F. Burlina and J. Offer, J. Pept. Sci., 2016, 22, $360-367$.

7 C. Toonstra, M. N. Amin and L.-X. Wang, J. Org. Chem., 2016, 81, 6176-6185.

8 C. G. Bochet, Angew. Chem., Int. Ed., 2001, 40, 2071-2073.

9 N. De Alwis Watuthanthrige, P. N. Kurek and D. Konkolewicz, Polym. Chem., 2018, 9, 1557-1561.

10 K. Hiltebrandt, M. Kaupp, E. Molle, J. P. Menzel, J. P. Blinco and C. Barner-Kowollik, Chem. Commun., 2016, 52, 9426-9429. 
11 K. R. Wilson, S. Sedberry, R. Pescatore, D. Vinton, B. Love, S. Ballard, B. C. Wham, S. K. Hutchison and E. J. Williamson, J. Pept. Sci., 2016, 22, 622-627.

12 M. R. Levengood, X. Zhang, J. H. Hunter, K. K. Emmerton, J. B. Miyamoto, T. S. Lewis and P. D. Senter, Angew. Chem., Int. Ed., 2017, 56, 733-737.

13 H. Katayama and H. Hojo, Org. Biomol. Chem., 2013, 11, 4405-4413.

14 M. Lapeyre, J. Leprince, M. Massonneau, H. Oulyadi, P.-Y. Renard, A. Romieu, G. Turcatti and H. Vaudry, Chem. - Eur. J., 2006, 12, 3655-3671.

15 A. Isidro-Llobet, M. Álvarez and F. Albericio, Chem. Rev., 2009, 109, 2455-2504.

16 T. Yamada and H. Kitagawa, J. Am. Chem. Soc., 2009, 131, 6312-6313.

17 D. J. Lun, G. I. N. Waterhouse and S. G. Telfer, J. Am. Chem. Soc., 2011, 133, 5806-5809.

18 R. K. Deshpande, J. L. Minnaar and S. G. Telfer, Angew. Chem., Int. Ed., 2010, 49, 4598-4602.

19 A. Carne'-Sa'nchez, J. Albalad, T. Grancha, I. Imaz, J. Juanhuix, P. Larpent, S. Furukawa and D. Maspoch, J. Am. Chem. Soc., 2019, 141, 4094-4102.

20 G. Nickerl, U. Stoeck, U. Burkhardt, I. Senkovska and S. Kaskel, J. Mater. Chem. A, 2014, 2, 144-148.

21 A. G. M. Barrett, D. Hamprecht, R. A. James, M. Ohkubo, P. A. Procopiou, M. A. Toledo, A. J. P. White and D. J. Williams, J. Org. Chem., 2001, 66, 2187-2196.

22 (a) P. S. Reiss, M. A. Little, V. Santolini, S. Y. Chong, T. Hasell, K. E. Jelfs, M. E. Briggs and A. I. Cooper, Chem. - Eur. J., 2016, 22, 16547-16553; (b) A. Carne'-Sa'nchez, G. A. Craig, P. Larpent, V. Guillerm, K. Urayama, D. Maspoch and S. Furukawa, Angew. Chem., Int. Ed., 2019, 58, 6347-6350.

23 H. Liu, L. Chen and J. Ding, RSC Adv., 2016, 6, 48884-48895.

24 R. W. Flaig, T. M. Osborn Popp, A. M. Fracaroli, E. A. Kapustin, M. J. Kalmutzki, R. M. Altamimi, F. Fathieh, J. A. Reimer and O. M. Yaghi, J. Am. Chem. Soc., 2017, 139, 12125-12128.

25 J. Bitta and S. Kubik, Org. Lett., 2001, 3, 2637-2640.

26 R. K. Deshpande, J. L. Minnaar and S. G. Telfer, Angew. Chem., Int. Ed., 2010, 49, 4598-4602.

27 A. Carne-Sanchez, G. A. Craig, P. Larpent, T. Hirose, M. Higuchi, S. Kitagawa, K. Matsuda, K. Urayama and S. Furukawa, Nat. Commun., 2018, 9, 2506.

28 X. Liu, X. Wang, A. V. Bavykina, L. Chu, M. Shan, A. Sabetghadam, H. Miro, F. Kapteijn and J. Gascon, ACS Appl. Mater. Interfaces, 2018, 10, 21381-21389. 


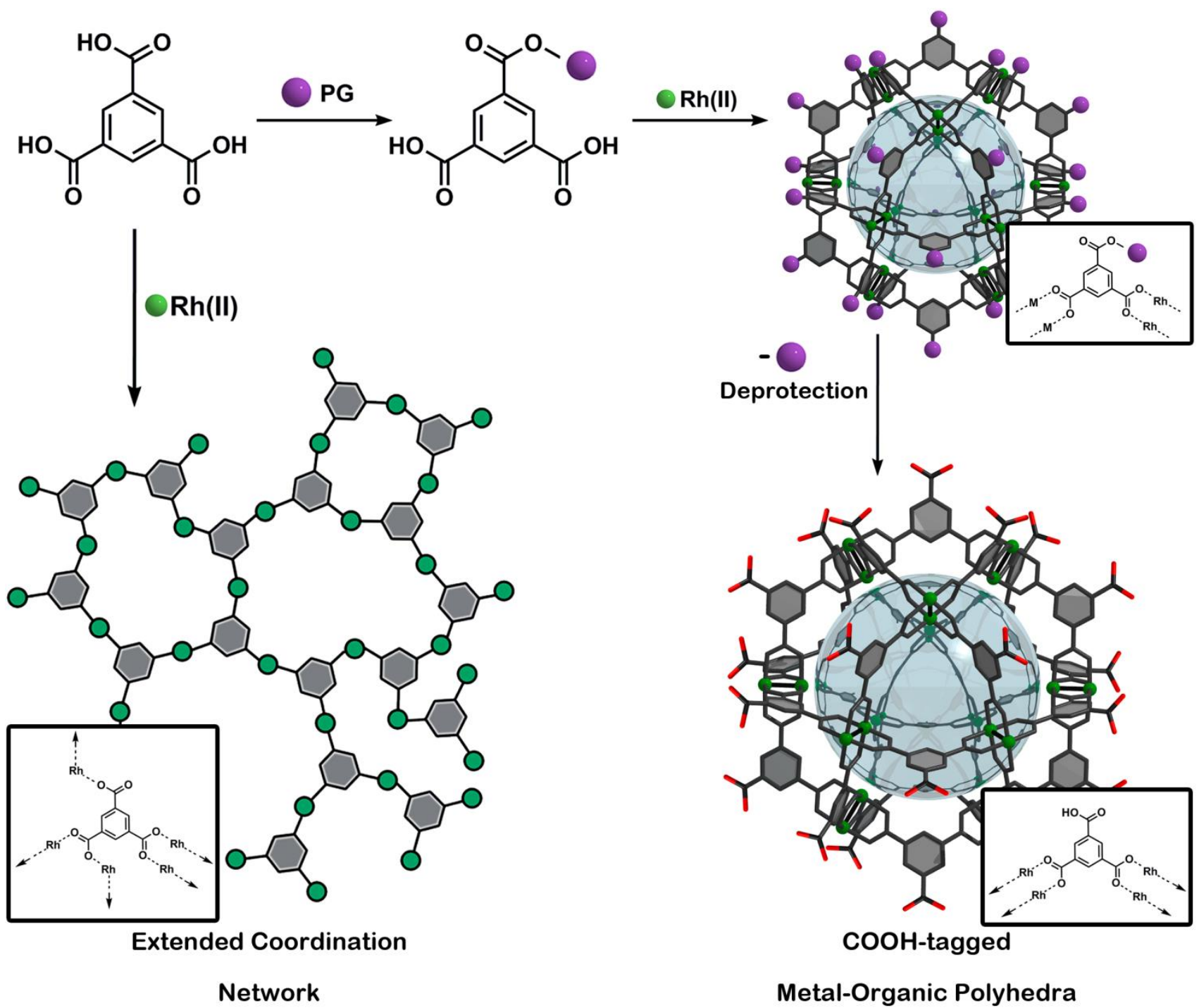

Fig. 1 Scheme of the protecting group strategy to synthesise a COOH-tagged cuboctahedral Rh(II)-based MOP. 
a)

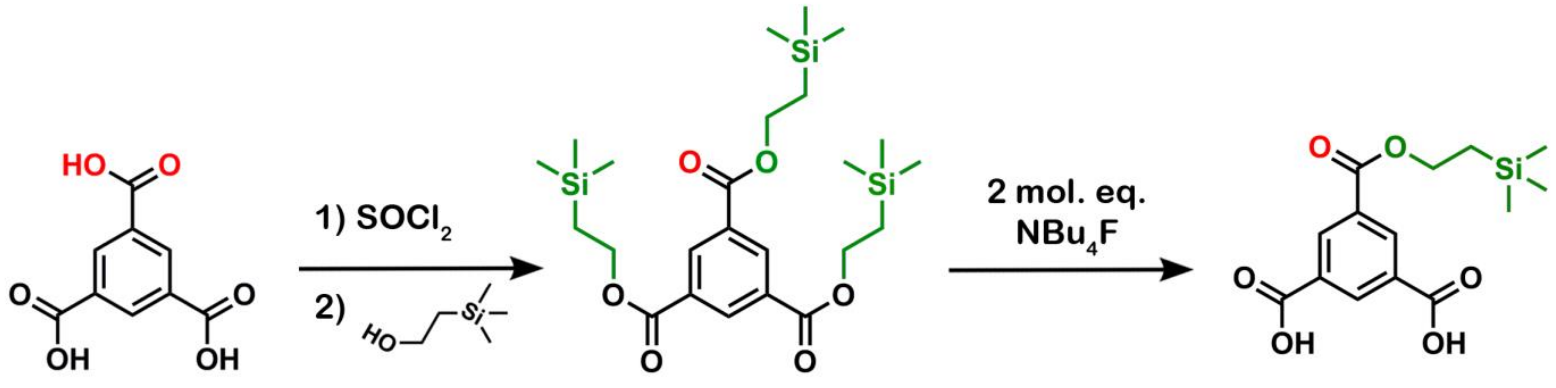

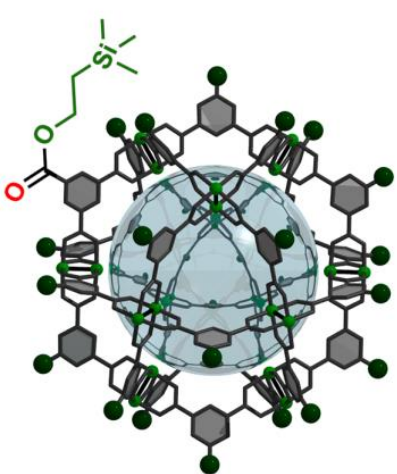

COOTSE-RhMOP

btc-COOTSE

$\mathrm{H}_{2}$ btc-COOTSE

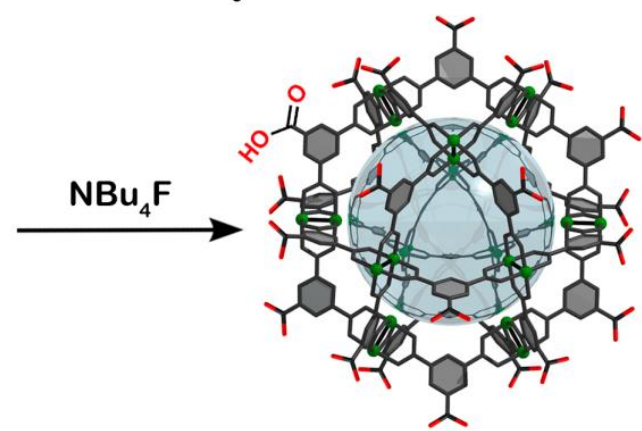

COOH-RhMOP

b)

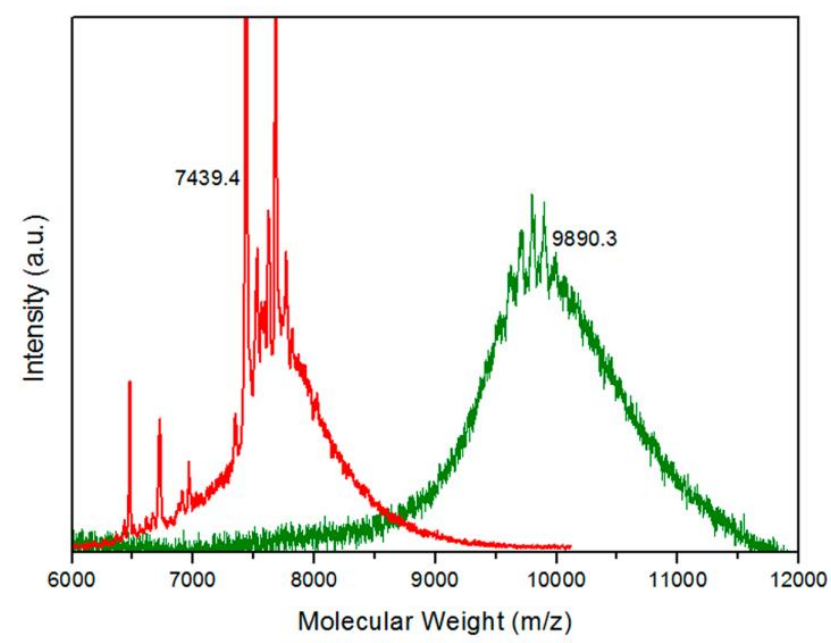

c)

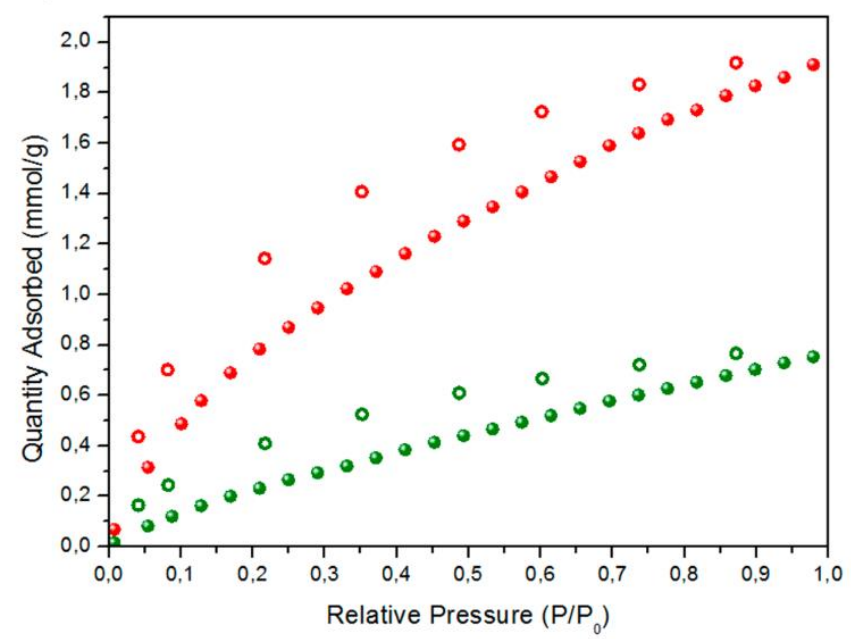

Fig. 2 (a) Scheme of the strategy used to synthesise COOH-RhMOP. (b) MALDI-TOF of COOTSE-RhMOP (green) and $\mathrm{COOH}-\mathrm{RhMOP}$ (red). (c) $\mathrm{CO}_{2}$ adsorption isotherm at $298 \mathrm{~K}$ of COOTSE-RhMOP (green) and COOH-RhMOP (red). 
a)

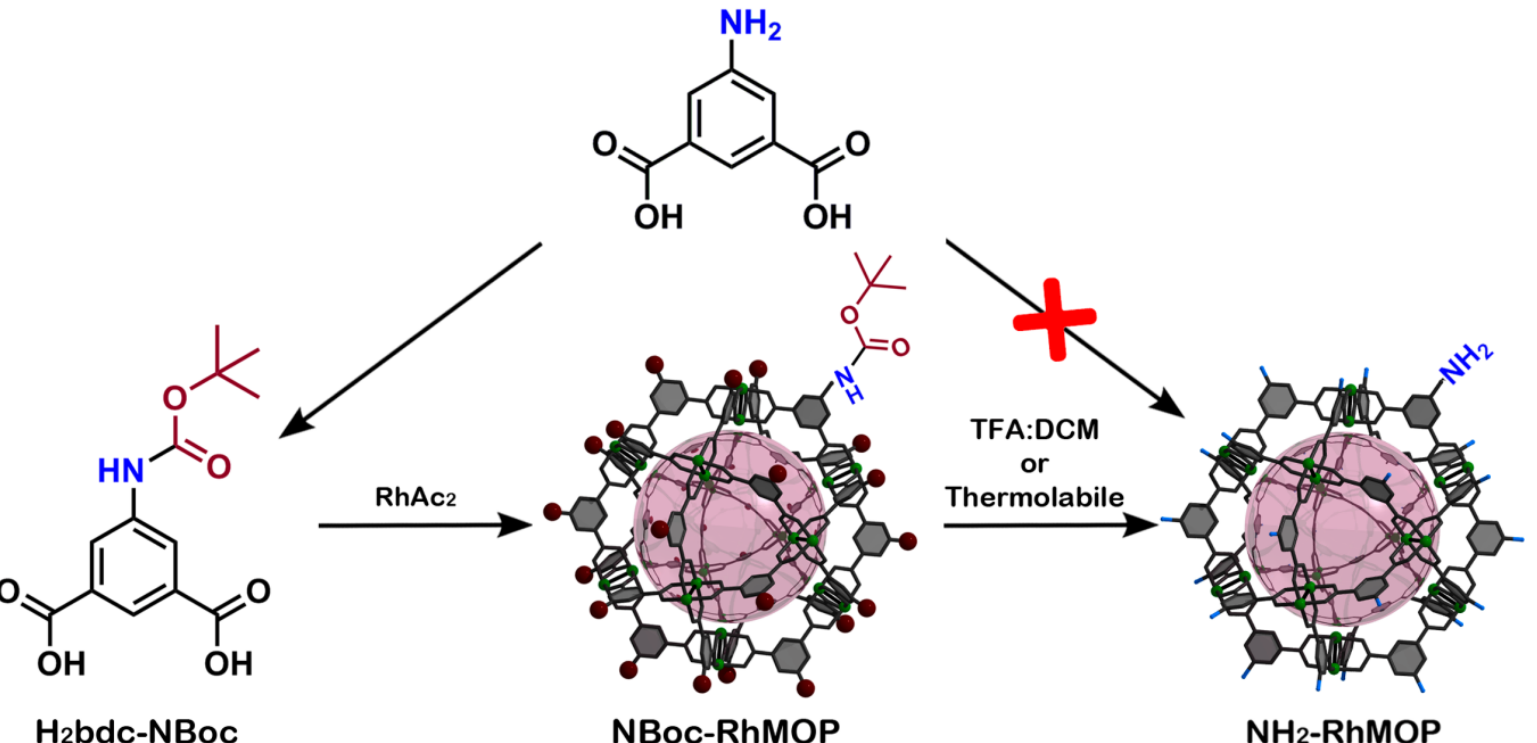

b)

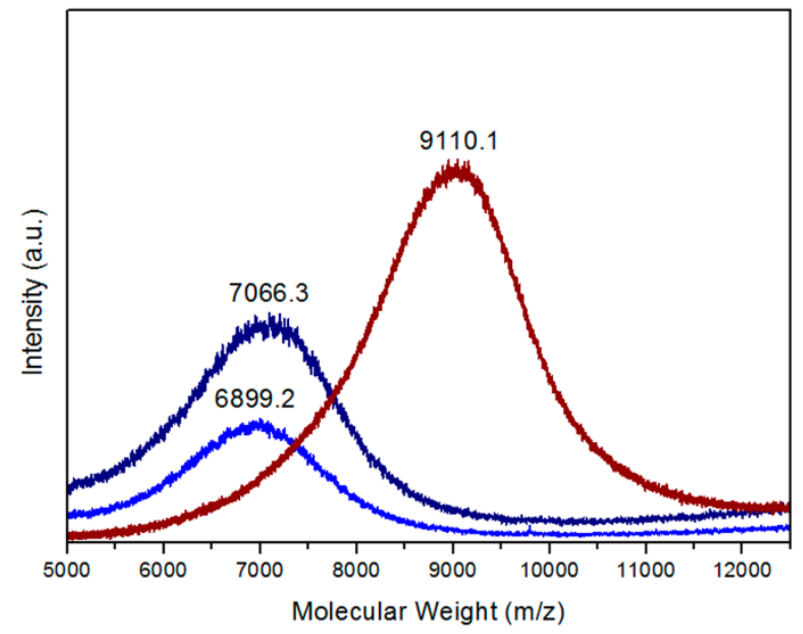

c)

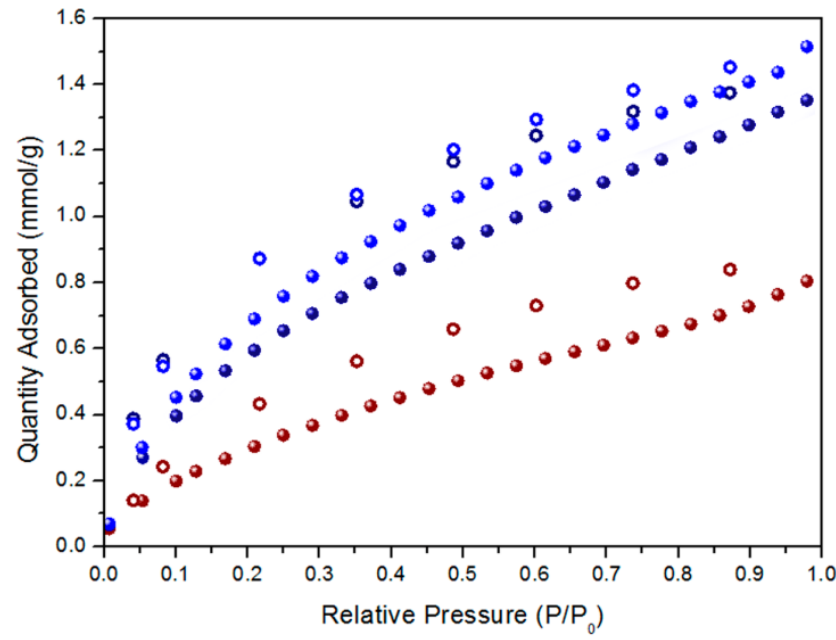

Fig. 3 (a) Scheme of the strategy used to synthesise $\mathrm{NH}_{2}$-RhMOP. (b) MALDI-TOF spectra of the NBoc-RhMOP (red) and the $\mathrm{NH}_{2}-\mathrm{RhMOP}$ prepeared by thermolysis (navy) or by the TFA based deprotection (blue). (c) $\mathrm{CO}_{2}$ adsorption isotherm at $298 \mathrm{~K}$ of the NBoc-RhMOP (red) and the $\mathrm{NH}_{2}-\mathrm{RhMOP}$ prepeared by thermolysis (navy) or by the TFA based deprotection (blue). 